\title{
PHILOLOGY
}

\section{ПРОБЛЕМЫ ПЕРЕВОДА ФРАЗЕОЛОГИЧЕСКИХ ЕДИНИЦ С НЕМЕЦКОГО ЯЗЫКА НА УЗБЕКСКИЙ}

\author{
${ }^{1}$ к.ф.н., дочент Имяминова Шухратхон Салижсановна, \\ ${ }^{2}$ Ачилова Нилуфар Мансуровна, \\ ${ }^{3}$ Комолова Шахноза Адхамовна, \\ ${ }^{4}$ Саидова Дурдона Акром қизи
}

Узбекистан, Ташкент, Национальный университет Узбекистана имени Мирзо Улугбека

${ }^{1}$ Заведующая кафедрой немецкой филологии, факультет зарубежной филологии, НУУз;

${ }^{2}$ Преподаватель кафедрой немеикой филологии, факультет зарубежной филологии, НУУз;

${ }^{3}$ Преподаватель кафедрой немеикой филологии, факультет зарубежной филологии, НУУз;

${ }^{4}$ Преподаватель кафедрой немеикой филологии, факультет зарубежной филологии, НУУз

DOI: https://doi.org/10.31435/rsglobal_ws/30112019/6790

\section{ARTICLE INFO}

Received: 16 September 2019

Accepted: 23 November 2019

Published: 30 November 2019

\section{KEYWORDS}

phraseological units, translation, meaning, analysis, folk, image, method, unit.

\begin{abstract}
The following article is devoted to the issues of translating phraseological units from German into Uzbek. The article highlights the role of phraseological units in the language, and emphasizes the importance of taking into account the customs and mentality of two nations while translating.
\end{abstract}

Citation: Имяминова Шухратхон Салижановна, Ачилова Нилуфар Мансуровна, Комолова Шахноза Адхамовна, Саидова Дурдона Акром қизи. (2019) Problems in Translating Phraseological Units from German into Uzbek. World Science. 11(51), Vol.4. doi: 10.31435/rsglobal_ws/30112019/6790

Copyright: (C) 2019 Имяминова Шухратхон Салижановна, Ачилова Нилуфар Мансуровна, Комолова Шахноза Адхамовна, Саидова Дурдона Акром қизи. This is an open-access article distributed under the terms of the Creative Commons Attribution License (CC BY). The use, distribution or reproduction in other forums is permitted, provided the original author(s) or licensor are credited and that the original publication in this journal is cited, in accordance with accepted academic practice. No use, distribution or reproduction is permitted which does not comply with these terms.

Признавая важность фразеологии в лингвистике, мы бы хотели подчеркнуть важность их перевода с немецкого языка на узбекский. При переводе фраз обнаруживаются такие проблемы как частичное соответствие, полное соответствие и несовместимость.

Перевод фразеологических единиц

Перевод немецких фразеологизмов на узбекский язык представляет некоторые трудности, возникающие в процессе переводческих исследований. Существуют разные способы перевода немецких фразеологизмов на узбекский язык. Например, перевод такого фразеологизма как “seinen Anfang nehmen (od.kriegen)" - на немецком языке - “anfangen”, а узбекское - «бошламоқ». Эту же фразу с той же фразеологией можно найти в переводе произведения Г.Гессе под названием «Степной волк», например: "Damals hatte meine Vereinsamung ihren Anfang genommen" ("Steppenwolf”, стр.75).

Известный переводчик М.Акбаров перевел на узбекский язык эту фразу следующим образом: «Ўшанда менинг ёлғизликдаги, ғарибликдаги хаётим бошланган эди» (“Чўл бўриси”, стр. 70).

Как мы видим, из этих примеров, фразеологизмы в обоих языках полностью совпадают по структуре и по значению. 
В результате анализа можно сделать вывод, что некоторые фразы в немецком языке соответствуют значению фразеологизмов в узбекском языке. Такие случаи совместимости облегчают процесс перевода и проясняют смысл.

Этот вид соответствия ситуаций помогает легко перевести и дать полное значение фразеологической единицы.

В конце концов, главная цель переводчика — это перевести фразеологическую единицу на один язык с той же фразеологической единицей в конце. Эта цель не всегда может быть достигнута в переводе, потому что она требует большого мастерства со стороны переводчика. Стоит отметить, что перед тем, как переводить произведение, переводчик также должен решить, сможет ли он перевести его должным образом.

\section{Несоответствия в переводе фразеологических единиц}

Существует несколько трудностей при переводе немецких фразеологизмов на узбекский язык. Одним из таких случаев является несоответствие в переводе немецких фразеологизмов. Это отражает неспособность напрямую перевести смысл внутренних компонентов немецкой фразеологии. В то время как внутренние компоненты фразеологических единиц в немецком языке имеют правильное значение, общее значение фразеологии построено на очень сильном образе. Таких фраз следует избегать без дословного толкования. Если это произойдет, то фразеология теряет свое первоначальное значение. Например, фразеологизм “die Augen schließen” в переводе с немецкого означает “sterben”. Узбекское значение этой же фразеологической единицы аналогично немецкому значению, “кўз юммок” то означает «ўлмоқ». Но когда эта фразеология переводится прямым способом и получается «бирор ким ёки нарса хақида унутмоқ», ее значение теряется. Ведь даже простой спящий может закрыть глаза, может уснуть, закрыв глаза. В то же время фразеология не используется в буквальном смысле.

Давайте посмотрим на фразу с тем же фразеологизмом: "Dankbar schloss ich die Augen und nippte am Elixier" (“Steppenwolf”, стр.191). Мирзали Акбаров переводит эту фразу следующим образом: “Мен мамнуният билан кўзларимни юмдим ва хаёт эликсерини ичишда давом этдим.” (“Чўл бўриси”, стр. 99). Фразеология в этом предложении не используется в его первоначальном значении.

\section{Выражение фразеологии другими единицами в переводе}

Передача фразеологических единиц другими единицами в переводе является одним из способов перевода в переводоведении. В то же время перевод с немецкого языка другой единицей, близкой по смыслу фразеологии, но без фразеологии, является отражением этого условия в переводе.

Правда, что немецкая фразеология теряет свой имидж при переводе на узбекский язык. Рассмотрим следующий пример. Фраза "zur Ruhe kommen" в переводе в немецком имеет значение “sich beruhigen". В узбекском это “ором олмоқ” также значит «тинчланмоқ». Теперь рассмотрим этот пример в предложении. "Statt deine Welt zu verengern, deine Seele zu vereinfachen, wirst du immer mehr Welt, wirst schließlich die ganze Welt in deine schmerzlich erweiterte Seele aufnehmen mussen, um vielleicht einmal zum Ende, zur Ruhe zu kommen” („Steppenwolf“, стр. 72).

М. Акбаров перевел эту фразу: «Вместо того, чтобы сузить свой собственный мир и упростить свое сердце, теперь вы должны переместить сердце в более широкий мир и, в конечном счете, печаль вашего сердца, достигнет конца света» (“Steppenwolf”, стр. 38).

Фраза «zur Ruhe Kommen», выраженная в данном случае, не совсем означает «спокойный», скорее «вечное спокойствие». Здесь перевод фразеологии выражается другой единицей, а не фразеологической.

В целом, несоответствия в переводе или выражении другими единицами гарантируют, что перевод не будет единообразным.

Еще одна важная группа фраз - это очень малоизученные пословицы и поговорки. Однако следует отметить, что богатство языка народа измеряется богатством фразеологического слоя, его красочных слов. Потому что во фразах, поговорках и притчах отражены проблемы жизни, тяжелый труд, печаль, счастье, успех и поражение людей. Не только люди, но и ученые играют большую роль в создании и передаче их читателю. Интересно то, что есть много пословиц и поговорок, которые семантически идентичны по форме и значению в разных языках [1]. Например, узбекский народ использует пословицы, которые 
существуют более чем в 100 языках мира, такие как «Семь раз отмерь, а потом отрежь», «Гора не встречается с горой, а человек встречается с человеком».

Фразеологические единицы образуются не в речи, в которой используются слова или фразы, а на том же языке, что и слова. Следовательно, фразеология - это явление языка, а не явление речи.

Основные направления фразеологических исследований. Одним из основных направлений фразеологических исследований является развитие сравнительных исследований, которое может быть продиктовано двуязычной ситуацией с двумя официальными языками: русским и узбекским. Тем не менее, следует отметить, что исследуются не только фразеологизмы этих двух языков. Существует значительное количество работ, посвященных сравнительному изучению славянских, германских, тюркских и других семей и групп языков, таких как английский, немецкий, французский, испанский, португальский, турецкий, узбекский, арабский, таджикский, польский, болгарский, украинский, белорусский, вьетнамский и другие. Пожалуй, наиболее типичной парой сравниваемых языков является англо-русский (или русско-английский), реже встречаются исследования русско-англоузбекских фразеологизмов. Англо-турецкие сравнительные исследования фразеологизмов также довольно многочисленны. Как правило, ученые-фразеологи выбирают фразеологические запасы двух или трех языков для анализа, но есть также работы, которые посвящены сравнительному изучению фразеологизмов на четырех или даже пяти языках.

Первые глубокие сравнительные исследования фразеологизмов в русском языке и некоторых германских языках можно проследить от конца 1960-х и начала 1970-х годов (Гатиатуллина 1968, Долгополов 1973).

В следующем десятилетии появились новые важные исследования, которые заложили основу для дальнейшего развития сравнительной фразеологии (Юсупов, 1980, Байрамова, 1983, Арсентьева, 1983 и др.). Работы Э. Солодуцко, посвященные исследованию фразеологических переводных заимствований и причине фразеологического параллелизма в сравниваемых языках, имели особенно большое значение (Солодуцко, 1983).

Основные методы и принципы сравнительных фразеологических исследований были дополнительно сформулированы и разработаны в 1990-х годах. Анализ фразеологических запасов различных языков стал в центре внимания многих ученых в этот период, а также количество защищенных диссертаций увеличилось в несколько раз. Одну из причин можно увидеть в открытии двух Ученых советов, работающих в области сравнительных и типологических исследований.

Сравнительный анализ русских, немецких и английских фразеологизмов антропоцентрического характера, проведенный Е. Арсентьевой, привел к многочисленным исследованиям обширных слоев фразеологии, в которых основное внимание было уделено изучению антропоцентрических фразеологизмов на разных языках (Арсентьева 1993). В этом отношении антропоцентрический подход остается наиболее важным за последние два десятилетия.

В центре внимания фразеологов - фразеологическое описание человека, его основных черт характера, внешности, физических, моральных, эмоциональных характеристик, способов поведения. Появилось много работ, посвященных сравнительному анализу, изучению некоторых определенных фразеосемантических групп, связанных с категориями основных социальных ценностей людей разных культур, таких как семья, религия, деньги, аксиологическая двойственность счастья/несчастья и другие. (Сафина 2002, Байрамова 2012 и др.).

Конец XX и начало XXI веков также стали свидетелями интенсивного развития теории фразеологического значения. Большое внимание было уделено исследованию таких коннотационных компонентов фразеологического значения, как функциональностилистический, экспрессивный и оценочный. Парадигматические отношения фразеологизмов, а также взаимосвязи внутренней формы, мотивационного базиса, образа ФЕ и процесса создания фразеологических эвфемизмов также были предметом многих исследований (Макарова 1999, Салиева 2005, Арсентьева 2012, и другие.).

Лингвокультурологический подход к изучению фразеологических единиц появился в 1990-х годах. Его основной целью является установление национально-культурных особенностей фразеологических запасов разных языков. Фразеологические единицы анализируются с точки зрения репрезентации лингвокультурных явлений разных обществ с их 
собственными системами социально-нравственных ценностей, национальным менталитетом и отражением во фразеологических запасах языков стало главной проблемой исследований. Как правило, предметом фразеологических исследований являются фразеологизмы с компонентами, характеризующимися частотой встречаемости. Среди таких компонентов мы можем найти имена животных, птиц, части человеческого тела, имена разных цветов, собственные имена. (Ибрагимова 1993, Пименова 2002, Ганиева 2012 и др.).

Среди других направлений исследований следует назвать исследования фразеологизмов, принадлежащих к определенному грамматическому классу, таких как словесные, прилагательные или библейские ФЕ (Мендельсон 2002, Семушина 2004, Каримова 2005, Жолобова 2005 и др.). Целью исследований, большинство из которых были сравнительными, было изучение малейших особенностей в грамматической, семантической и компонентной структуре данных единиц.

Лингвокультурологический подход к изучению фразеологизмов тесно связан с когнитивно-интерпретационными парадигмами исследования, в которых различные концепции привлекают особое внимание ученых. В целом когнитивный подход был довольно популярен среди исследователей разных школ за последнее десятилетие. Такие понятия, как «пространство и время», «Бог», «сердце» и т. д., особенно привлекли специалистов по фразеологии (Игнатьева 2004, Афанасьева 2007, Базарова 2011). В конечном итоге основными целями таких исследований было выявление национальных особенностей языковой «картины мира» сквозь призму фразеологии, определение универсальных коммуникативно-прагматических категорий и аксиологических аспектов в различных лингвокультурах. Контекстный или функциональный аспект исследования становится все более популярным в наши дни. Этот подход предполагает изучение контекстуального поведения и функциональной значимости фразеологических единиц в различных типах текстов. Различные способы случайного использования ФЕ и их различные контекстуальные трансформации имеют первостепенное значение из-за высокой эмоциональноэкспрессивной коннотационной ценности таких трансформаций (Давлетбаева 2006, Абдуллина 2007, Зыкова 2010). Коллективная рукопись фразеологии ученых, основанная на материале нескольких языков (русский, английский, немецкий, испанский и узбекский), обобщает полученные результаты и наглядно демонстрирует преобладающее сходство таких трансформаций и их стилистический эффект (Арсентьева 2009).

Другой перспективный и интересный аспект исследования связан с проблемой перевода фразеологизмов английских и узбекских писателей и поэтов с одного языка на другой. Среди наиболее важных работ достаточно упомянуть кандидатские диссертации молодых ученых, в которых рассмотрены фразеологические единицы, использованные в произведении В. Шекспира. Это такие авторы как В. Коллинз и английские поэты XVIII и XIX веков, с одной стороны, и А. Навои, - с другой стороны, и способы их перевода с одного языка на другой (Аюпова 2001, Щербакова 2003, Медведева 2007, Каюмова 2010). Проблема адекватности перевода, как правило, находится в центре внимания, поскольку исследователи выделяют наиболее частые и адекватные способы перевода фразеологических единиц, характерные для того или иного автора, и особенности перевода трансформированных ФЕ в разные типы контекста. Практическая ценность таких исследований неоспорима.

Немецкий язык также богат идиомами. Например: Die Augen in die Hand nehmen смотреть внимательно, sich die Beine in den Leib stehen (lange warten) - долгое ожидание, ins Gras beisen - умереть, den Mund halten (die) schweigen) - замолать.

Как показывают приведенные выше примеры, все компоненты идиом являются переносимыми, что означает, что они не могут быть правильно поняты [1].

Идиомы, согласно А.А. Реформатскому, являются лексическими единицами, которые тесно связаны с местом, временем и даже отдельными явлениями, которые связаны с событием и представляют каждый язык отдельно, но не напрямую - поэтому не могут быть правильно переведены [2].

Хотя идиомы являются дословными, они всегда имеют семантическое различие между выражением отношения субъекта к объекту. Например, идиома das Kind mit Bade ausschütten переводится на узбекский язык как «салла деса каллани олиб келмоқ» и образно говорит «нодонлик», «билимсизлик». 
Идиомы - это фразы, которые давно существуют в языке. Их нельзя анализировать как слова, единицы. Нежелательно анализировать, переводить, или понимать идиомы отдельно, потому что истинное значение идиом не зависит от значения слов в идиомах.

А.А. Реформацкий ссылается на идиому, цитируя источники происхождения, а также на цитаты из фольклорных, писательских, философских и публицистических работ [3]. Согласно Руди Конрад, идиомы являются морфемоподобными структурами, и общее значение не зависит от значения слов, взятых отдельно в содержании идиом [4].

По словам О. Ахмановой, идиома - это единица в языке, отличающаяся своей синтаксической и семантической структурой [5]. Следовательно, идиома формируется из взаимосвязанных выражений. Например: sich kein Bein ausreißen [6] - вода не достигает лодыжек мира. Mit Ach und Krach - еле как, zwei Fliegen mit einer Clappe schlagen - убить двух зайцев одной стрелой, Pech haben - означает «быть несчастным».

Еще одной особенностью идиом является выражение общей концепции. Глагол “ $Z u$ Kreuz kriechen" переводится на узбекский язык с основным значением «хор бўлмоқ», «auf der Bärenhaut liegen”- ,faulenzen“ - на узбекский «дангасалик қилмоқ», глагол Sand in die Augen streuen - ,, belügen“ на узбекском «алдамоқ», «durch die Lappen gehen» - в узбекском «секинлик билан жуфтакни ростламоқ».

Вербальные идиомы, которые представляют основное значение идиом, получены из значений, которые они содержат, и не могут быть иначе. Например, таким образом переводятся следующие выражения: «ins Auge fallen» (bemerkbar sein) на узбекский язык «кўзга ташланмоқ», «sich den Kopf zerbrechen» (angestrengt nachdenken) - «уййамоқ», «gleiche Brüder - gleiche Kappen виноградные лозы, как фрукты в саду, den Kopf verlieren чувствовать головокружение.

Однако ни один глагол в идиоме не понимается в чистом смысле, поскольку он всегда имеет переносный смысл. Пример: Ja lieber Junge, wir sind eben nicht auf den Kopf gefallen, wir riechen alles. - Да, нет, это не глупо замечать. Неоправданные глагольные идиомы состоят в том, что их значения не состоят из их первоначального значения. Идиомы, связанные с идиомами, иногда можно объяснить этимологически-историческим подходом. Следует отметить, что основным критерием является субъективный подход. Это зависит от уровня динамики. Например: Auf der Bärenhaut liegen - в узбекском языке: «дангасалик қилмоқ» связана со значением слова «медведь» и характером этого животного, поскольку «медведь» очень ленивое, но сильное животное. Существует мнение, что сон на его коже также вызывает ленивость.

В отношении следующих идиом возникают вопросы относительно того, являются ли они оригинальными идиомами. Например: «jemanden auf die Finger sehen» (genau beobachten) идиома «правильно смотреть вверх», «смотреть», например «etwas auf den Fingern saugen» (sich etwas ausdenken, изобретать).

В этих примерах заслуживающее внимания слово Finger. Потому что вышеприведенные идиомы на узбекском языке не могут быть поняты фразой «смотреть на палец».

Идиома существует в каждом языке в течении многих лет, и продолжает развиваться и процветать. Потому что идиомы появляются в языках как оригинальные стабильные соединения.

Если общее значение фразеологизмов совпадает со значением компонентов, то это называется идиоматизацией.

Сильные выразительные, образные выражения делают речь активным средством, позволяя ей быть острым и убедительным визуальным инструментом в устной речи, художественной литературе и публицистике. Идиомы являются мощным средством создания эмоциональной картины событий в персонализации речи персонажей при описании образа героя. Иногда авторы частично меняют идиомы глагола, чтобы соответствовать цели, контексту. Существуют некоторые трудности при переводе идиом с немецкого на узбекский язык, поскольку компоненты идиомы не могут быть переведены непосредственно с одного языка на другой. Пример: «Die Augen sind größer als Magen». При переводе идиомы на узбекский язык, нет необходимости переводить ее вертикально, а скорее сформировать соединение, соответствующее этой идиоме в узбекском языке. Перевод этой идиомы прямо на узбекский означает буквально что-то другое. Его основное значение - «не есть», «жадный», «заграбастать, хапнуть как можно больше», но буквально означает «глаза больше, чем желудок». Например: «Hat Hänschen nicht aufgegessen?» - Nein, seine Augen Waren mal wieder größer als sein Magen. «Разве Хеншон не ел?» 
Выводы. Анализ наиболее важных работ, а также основных тенденций в изучении фразеологии исследователями показывает высокую потребность в изучении фразеологии. Его главной особенностью является сравнительный анализ фразеологизмов языков, принадлежащих к разным языковым группам и семьям, в том числе даже таких экзотических языков, как немецкий и узбекский. Многие выдающиеся исследователи используют так называемый широкий подход к фразеологии, что означает исследование всех типов устойчивых выражений, включая паремиологические запасы языков. Такой подход помогает им обогатить различные сферы изучения языка, связанные со стабильностью и изменчивостью языковых ресурсов.

Изучение фразеологизмов на разных уровнях позволяет исследователям различать их изоморфные и алломорфные характерные признаки и доказывать системный характер фразеологического запаса языка. Результаты исследований, особенно докторских диссертаций, представляют большую теоретическую ценность и открывают новые перспективы в развитии фразеологии.

Можно также говорить о высокой практической ценности исследований многих выдающихся исследователей. Разработка основных проблем фразеографии и подборка разных типов одноязычных, двуязычных и многоязычных фразеологических словарей, некоторые из которых не имеют конкурентов в мире, являются неопровержимым доказательством этого.

\section{ЛИТЕРАТУРА}

1. Г.З. Пермяков. 300 allgemeingebräuchliche russische Sprichwörter und sprichwortliche Redensarten (Ein illusriertes Nachschlagewerk für Deutschsprechende). Moskau, „Ruski jasik“, VEB Enzyklopädie, Leipzig, 1985. М. Садыкова. Краткий словарь Узбекско-русских поговорок-притч. Ташкент, "Укитувчи", 1993. Frey Christa, Herzog Annelies, Michel Artrur, Schutze Ruth. "Deutsche Sprichwörter für Ausländer”. VEB Enzyklopädie, Leipzig, 1979. М.Я. Цвиллинг. Русско-немецкий словарь поговорок и притч. М., Русский язык, 1984. Sprichwort-Wahr" s Wort M., Prosveshenie, 1980. Пошали Усман, Равшан Маматов. Немецкие народные пословицы и их узбекские эквиваленты. Учебное пособие, Самарканд, 1975.

2. Hans Schemann. Deutsche Idiomatic. Stuttgart, Dresden, 1993. Chernischewa I.I. Feste Wortkomplexe des Deutschen in Sprache und Rede. Moskau,1980. Iskos A., Lenkova A. Deutsche Lexicology. Leningrad,1970. Имяминова Ш. Немецкая лексикология (текст лекций). -Т.: Университет, 2000.

3. Реформатский А.А. Введение в языкознание. -Москва: Аспект Пресс, 2004, 128

4. Реформатский А.А. Введение в языкознание. -Москва: Аспект Пресс, 2004, 131

5. Rudi Konrad. Lexikon der sprachwissenschaftliche Termini, VEB. Bibliographisches Institut, Leipzig, 1988,96

6. Ахманова О.С. Словарь лингвистических терминов. - М .: Энциклопедия, 1969, 165

7. Annelies Herzog, Arthur Michel, Herbert Riedel. Deutsche idiomatische Wendungen für Ausländer. VEB, Verlag Enzyklopädie, Leipzig, 1976. 